\title{
EL GOBIERNO DE LOS SORDOS: EL DISPOSITIVO EDUCACIONAL*
}

\author{
Governing the Deaf: The Educational Apparatus
}

\author{
HERNÁN CUEVAS \\ Universidad Diego Portales, Santiago de Chile
}

\begin{abstract}
RESUMEN
Si bien la teoría política se ha ocupado recientemente de los "discapacitados" como parte de su interés por la diferencia y las minorías, no ha reparado suficientemente en la heterogeneidad de experiencias del cuerpo que se ocultan con el uso genérico de la categoría discapacitado y su aplicación acrítica para describir a las personas sordas. Este artículo plantea que la combinación de los estudios críticos sobre la sordera y la teoría política contemporánea permiten interpretar la sordera como un constructo fabricado en parte por el dispositivo educacional. El artículo analiza el dispositivo educacional oralista que aspira a determinar el campo de acción y la producción de subjetividad de los sordos según el modelo ideal de sujeto moderno y de ciudadanía democrática. Este modelo, construido sobre los supuestos del oralismo y el audismo, tiene efectos de imperialismo cultural y violencia simbólica sobre la población sorda que es gobernada en su cotidianeidad de manera opresiva. En oposición al dispositivo biopolítico de la educación oralista, la acción sociopolítica de los Sordos tiene el potencial de activar una biopolítica afirmativa del cuerpo y una política de la identidad y el reconocimiento de la cultura Sorda.
\end{abstract}

Palabras clave: Gubernamentalidad, educación, cultura Sorda, oralismo, audismo, imperialismo cultural, estigma y estereotipo.

\begin{abstract}
Although contemporary political theory has recently develop an interest in the 'disabled' as an expression of its concern with difference and minorities, it has not paid enough attention to the heterogeneity of bodily experiences described under the label disabled that is uncritically applied to the deaf. With the help of contemporary deaf studies and social and political theory, the article interprets deafness as a social construct that is instantiated partly though oralism and its educational dispositive. The article analizes the educational dispositive of oralism that aims at determining the field of action and the production of subjectivity of the deaf according to the model of modern subject and democratic citizen. This model, based on oralism and audism, has oppressive effects of cultural imperialism and symbolic violence over the deaf population. In opposition to the educational biopolitical dispositive of oralism, the sociopolitical action of the Deaf has the potential of activating an affirmative biopolitics of the body and a politics of identity and recognition of Deaf culture.
\end{abstract}

Key words: Governamentality, education, Deaf culture, oralism, audism, cultural imperialism, stigma and stereotype.

* $\quad$ Este trabajo ha sido posible gracias al apoyo del proyecto Fondecyt Nr. 1100877 Biological Citizenship y del proyecto Semilla de la Universidad Diego Portales New Formations of Citizenship. Agradezco los comentarios de los evaluadores anónimos de la Revista de Ciencia Política que sirvieron para aclarar importantes aspectos de mi argumento. 


\section{INTRODUCCIÓN}

Este artículo se basa en mi propia investigación empírica cualitativa y la dirección de estudiantes tesistas de pre y postgrado sobre ciudadanía, organizaciones de pacientes, enfermedad crónica, discapacidad y sordera. ${ }^{1}$ Aunque tuve una intuición previa, solo en el curso de mi investigación llegué a concluir que las observaciones y conocimientos empíricos podían ser mejor comprendidos bajo el prisma de algunos conceptos de la teoría política contemporánea en combinación con algunos de los conceptos desarrollados por los estudios críticos de la sordera (y secundariamente sobre la salud, la enfermedad y la discapacidad). Y si bien la teoría política se ha ocupado recientemente de minorías de enfermos crónicos y discapacitados como parte de su interés por la diferencia (Arneil, 2009; Young, 1990), no ha reparado suficiente en la heterogeneidad de experiencias e identidades que ocultan incluso dichas categorías de personas diferentes (Dhamoon, 2009).

Es usual encontrar en la literatura especializada (principalmente en la sociología de la discapacidad y los estudios sobre la sordera) relatos acerca de la evolución que ha tenido la representación de la discapacidad en la medicina y las ciencias humanas. De este modo, las personas con habilidades y condiciones especiales han sido representadas culturalmente, clasificadas, y tratadas social, política y médicamente de diferente manera a lo largo de la historia y en distintas latitudes. Estos estudios presentan frecuentemente una cierta evolución desde un paradigma tradicional en el que dominó la comprensión religiosa de la discapacidad, pasando luego a un paradigma biomédico racionalista, científico y patologizante que se vincula al proceso de secularización y la modernización social, para arribar más reciente a un paradigma social de la discapacidad que enfatiza la construcción social de la condición del cuerpo de las personas diferentes (Altman, 2001; Garland-Thomson, 1997; Shakespeare, 2006; Tremain, 2001; Williams, 2001). En términos generales, esta literatura muestra cómo la noción de normalidad corporal ha sido histórica y socialmente construida de modo relacional, oponiendo a la normalidad una serie de representaciones de otros anormales. Esta representación de la normalidad y la anormalidad se ha impuesto desde prácticas de conocimiento privilegiadas como la medicina y otras ciencias humanas como la pedagogía. Esta comprensión de la normalidad/anormalidad puede, sin embargo, ser desconstruida para desvelar su formación contingente, como por ejemplo lo realiza Dharmoon (2009) respecto de la sordera.

En este artículo me ocuparé específicamente de la sordera, que al decir de Dolnick (1993) es un caso único de "discapacidad". En este mismo sentido, uso el término

En el campo de la teoría política, el trabajo de Robert Sparrow $(2005 ; 2010)$ constituye una notable excepción al silencio generalizado sobre la sordera/Sordedad (Ladd, 2003). Por obvias limitaciones de espacio, no será posible en este artículo hacer una revisión del campo de la sociología de la discapacidad, contexto en el que podrían ser situados los estudios sobre la sordera/Sordedad. Más aún, como verá el lector atento, la propia categoría de discapacidad será problematizada a lo largo del artículo. Sin embargo, he tenido a la vista como telón de fondo la vasta literatura sociológica sobre la enfermedad crónica y la discapacidad. El lector interesado puede consultar el excelente Handbook of Disability Studies de Albrecht et al. (eds.) (2001), al que contribuyen algunos de los autores más reputados en el campo. Entre las recientes publicaciones es importante el libro de Ronald Berger Introducing Disability Studies (2013), que parece llamado a convertirse en un nuevo clásico sobre el tema. 
"discapacidad" entre comillas o con cautela debido a que los estudios críticos sobre la sordera han enfatizado que no se trataría de una discapacidad, sino de una categoría social en cierto sentido similar a la de las minorías lingüísticas o sexuales (Dhamoon, 2009; Dolnick, 1993; Sparrow, 2005).

Diferentes autores han descrito críticamente desde las perspectivas de la sociología de la discapacidad, los estudios de la discapacidad y los estudios de la sordera, las diferentes comprensiones que las sociedades han construido acerca de la sordera desde perspectivas predominantemente oyentes (Dhamoon, 2009; Ladd, 2003; Lane, 1984; 1992; Sacks, 2003). Este conjunto de trabajos muestran cómo la mirada médica llevó a objetivar la sordera y a regularla desde mediados del siglo XIX con resultados opresivos para los sordos. Solo recientemente -más precisamente a partir de los años 60- esta tendencia comenzó a cambiar (en la próxima sección volveremos sobre ello). Por su parte, Humphries y Padden (2005) realizan un relato de tintes más personales desde la perspectiva de académicos Sordos. Basándose principalmente en evidencia sociolingüística, histórica y etnográfica, Humphries y Padden (2005) proponen que los sordos poseen una cultura propia y particular. Estos autores definen la cultura Sorda a partir de sus creencias compartidas, prácticas comunes y, en especial, a la lengua que les es propia, el lenguaje de signos (Humphries y Padden, 2005: 1). Este conjunto de elementos distinguirían a los Sordos como una comunidad particular, diferente de la mayoría oyente, pero también distinta de otros sordos y de personas con dificultades para oír (hipoacúsicos). ${ }^{2}$

En las próximas páginas se analizarán algunas de las prácticas educativas implementadas con personas sordas con el propósito de mostrar de qué modo el dispositivo educativo gobierna esta población particular. Partiré por una afirmación que puede parecer algo rotunda: la educación es un medio para gobernar, es decir, es uno de los múltiples dispositivos que apalancan la lógica general del gobierno cuyo objetivo es siempre controlar y conducir la conducta de las poblaciones con vistas a ciertos fines (Ball (ed.), 1993; Grinberg, 2008; Peters et al., 2009). Desde esta perspectiva, en lugar de ser romantizada, la educación es concebida como una actividad alineada con una lógica unificada del poder cuyo fin es contribuir a gobernar las poblaciones de manera efectiva. En la búsqueda de su optimización para producir el gobierno de las poblaciones, esta lógica del poder se diferencia en múltiples modulaciones que dan pie a mecanismos específicos aplicados a grupos particulares. Surgen así una multiplicidad de pedagogías, con sus respectivos enfoques, técnicas y programas de intervención. En consecuencia, no hay una práctica educativa, sino un conjunto diferenciado y heterogéneo de dispositivos educativos que incluyen discursos, tecnologías, estrategias y tácticas que se ordenan para producir el

2 Siguiendo una común convención entre especialistas, reservamos la palabra Sordo con mayúscula para referirnos a personas cuya primera lengua es una lengua de signos y que comparten una (sub)cultura, y la palabra sordo con minúscula para las personas que padecen hipoacusia severa o que son sordos profundos desde el punto de vista médico (Dolnick, 1993; Sparrow, 2005). De modo paralelo, se ha propuesto la distinción entre Sordedad y sordera para distinguir la dimensión cultural y lingüística de la experiencia de los Sordos (Sordedad) de la descripción patologizante que hacen la medicina y la cultura oyente de la experiencia de los sordos (sordera) (Ladd, 2003). 
gobierno de poblaciones específicas. Como consecuencia, a nivel agregado se produce un resultado favorable al gobierno de la población en general.

Atendiendo a esta diferenciación funcional de la educación, en este artículo se analiza el gobierno por medio de la educación de una población particular: los sordos. Esta estrategia de selección de caso permite comprender no solo las particularidades de la educación de un grupo en un campo diferenciado, sino también nos permite comprender la común lógica del gobierno de la heterogeneidad social, que requiere de modulaciones específicas que se producen con el objetivo de regular la población en general.

El dispositivo educacional es importante, pues con la conjunta operación de sus saberes aplicados, instituciones y expertos, aspira a determinar el campo de acción de los sujetos y la producción de subjetividades. En la siguiente sección (2) se presenta en un nivel de observación macro el dispositivo educacional para sordos como una forma de gubernamentalidad moderna. Complementariamente, en la sección 3 se analiza el dispositivo educacional para sordos poniendo especial énfasis en algunos mecanismos y lógicas de regulación. Pero este ensayo quedaría incompleto si solo atendiera al dispositivo de poder educacional, pues para entender la dinámica completa del poder es necesario dar cuenta de la experiencia de Sordos que se oponen a la biopolítica de control implementada por el dispositivo educacional, que reivindica el lenguaje de señas, la afirmación de la cultura Sorda y su reconocimiento. Atendiendo a ello, la sección 4 ofrece un esbozo de las prácticas de libertad y formas de autogobierno promovidas por los Sordos, tema que esperamos desarrollar con el detalle merecido en otro artículo en elaboración. La conclusión retoma el tema del gobierno de los sordos ejercitado desde el dispositivo educacional oralista y las críticas de que ha sido objeto, y promueve decididamente una política de la identidad y reconocimiento de los Sordos y su cultura como una forma de autocomprensión alternativa. ${ }^{3}$

3 Las palabras reconocimiento, identidad y cultura son términos de uso cotidiano en el discurso de activistas $\mathrm{S}$ /sordos y forman parte del lenguaje de los estudiosos de la cultura Sorda como Lane (1992) y Ladd (2003). Aunque la motivación central de este artículo es mostrar cómo la teoría política puede iluminar el fenómeno de la sordera, he preferido mantener una cierta lealtad a la autocomprensión de las personas Sordas y su uso de esas ideas, alejándome así de los conceptos de la teoría de la política del reconocimiento de Charles Taylor (1994), que desarrolla las ideas de reconocimiento, política de identidad, cultura y multiculturalismo en los registros de la filosofía política comunitaria y la hermenéutica. Si bien la aplicación de la teoría de Taylor parece a primera vista muy sugerente -a causa de su énfasis en la cultura como fuente de demanda identitaria y política de grupos-, una lectura más cuidadosa la revela problemática. En primer lugar, debido a que sus conceptos de identidad, cultura y reconocimiento se apoyan en una figura del diálogo como proceso fundamentalmente oral y textual, lo que lo aleja de la experiencia de la sordedad (Ladd, 2003) y la cultura Sorda (Humphries y Padden 2005). En efecto, aunque Taylor $(1994,32)$ explícitamente se refiere al lenguaje en un amplio sentido como "modo de expresión", su argumentación posterior tiende a favorecer la oralidad y el texto y a ignorar otros registros simbólicos. En segundo lugar, estos conceptos se apoyan en una idea de autenticidad de tintes algo esencialistas debido a su énfasis en las ideas de origen y profundidad que se distancian de mi comprensión de la identidad y la cultura de las personas Sordas. En tercer lugar, las ontologías del sujeto de Foucault que aquí utilizo y la de Taylor son muy diferentes y su combinación requeriría de una reflexión demandante que no es el tema de este artículo. Sobre el particular, derivo al lector al excelente artículo de Allison Weir (2009). Finalmente, y tal vez más importante, la concepción de Taylor de la discapacidad $(1994,41-42)$ no es consistente con mis observaciones de la autocomprensión de los Sordos (ver además las críticas de Arneil (2009) a Taylor). En síntesis, si bien el uso de los conceptos de la política del reconocimiento de Taylor para estudiar las demandas de los Sordos es sugerente, esta debe ser considerada con cautela y sentido crítico, debido a las razones acá enunciadas brevemente. 


\section{GUBERNAMENTALIDAD Y EDUCACIÓN}

Hacia el final de su carrera intelectual Michel Foucault desarrolló el concepto de gubernamentalidad (2000a). Por medio de este neologismo vinculó los significados de los términos gobierno (gouvernement) o gobernar (gouverner) y racionalidad (rationalité) o mentalidad (mentalité), queriendo así enfatizar las cambiantes lógicas o racionalidades que dan forma al poder en situaciones históricas concretas (Foucault, 2000a).

Este concepto es un avance en el desarrollo de la analítica histórica del poder foucaultino. En efecto, el programa de investigación de la gubernamentalidad permite estudiar las lógicas o formas de pensamiento que estructuran el poder y sus finalidades y diferentes formaciones históricas. El poder como práctica de gobierno se refiere principalmente -aunque no únicamente- al conjunto de capacidades constitutivas de las conductas y los sujetos (Foucault, 2000a; Gordon, 1991) y su ejercicio consistiría en "guiar las posibilidades de conducta y disponerlas con el propósito de obtener posibles resultados" (Foucault, 2000a: 253). Así, la cuestión del gobierno de la conducta y las poblaciones pasa a ser central.

La investigación genealógica del concepto de gobierno emprendida por Foucault demuestra que en la historia del pensamiento político este también se refirió a las prácticas de control y conducción en general. Foucault propone rescatar este sentido más amplio del término gobierno, que habría sido característico en el siglo XVI y que se refería no solo "a estructuras políticas o a la dirección de los Estados", sino que también incluía "la forma en que podría dirigirse la conducta de los individuos o de los grupos" (Foucault, 2001: 253-254). Estudiar las lógicas de gobierno de la conducta humana "más allá del Estado" (Rose y Miller, 1992) nos insta a analizar las estrategias de gobierno que se instituyen por medio de variadas alianzas entre diferentes clases de autoridad social, algunas de carácter no político según las definiciones convencionales, como la educación.

Susana Grinberg, una de las investigadoras que ha desarrollado la agenda de estudios de la gubernamentalidad en el campo de la educación en América Latina define la gubernamentalidad como

el conjunto de prácticas mediante las cuales se puede constituir, definir, organizar, instrumentalizar las estrategias que los individuos en su libertad pueden establecer en relación con otros individuos libres para gobernarlos (Grinberg, 2008: 55).

Grinberg destaca correctamente que en sociedades liberales el poder de control se basa en tecnologías que conducen la capacidad de agencia de individuos libres (ver también Foucault, 2000a). De este modo, el gobierno funciona privilegiadamente por el autocontrol, sin necesidad de encierro ni de tácticas disciplinarias de instituciones, aunque, como se sabe, estas no desaparecen del todo. Las sociedades de control alinean al individuo libre con ciertas conductas deseadas y promovidas sistémicamente. Para ello desarrollan dispositivos como psicoterapias y terapias de autoayuda, consejos y asesorías familiares, tecnologías y terapias medicamentosas para lograr una mejor inclusión social, y una 
plétora de mecanismos meritocráticos que promueven la autosuperación por medio de sistemas de incentivos y desincentivos. Así, este sistema de premios y castigos conduce al individuo libre para que elija lo correcto y actúe adecuadamente.

La educación es uno de los campos más apropiados para el desarrollo de este programa de investigación del gobierno de la conducta de las poblaciones. La creciente influencia de Foucault sobre la pedagogía crítica en las últimas décadas es especialmente notable, debido a que su filosofía remueve buena parte de los fundamentos de la pedagogía y los educadores: la verdad, el conocimiento, la ilustración, la civilización, la autonomía, la libertad, la equidad y la formación moral (Ball et al. 1993; Grinberg, 2008; Peters et al. 2009). Gracias a estos estudios de la gubernamentalidad y la educación podemos develar cómo participa el dispositivo educacional en la formación, organización y regulación de los individuos en general, y cómo lo hace su particular modulación oralista en la formación de los sordos.

Otro aspecto de la analítica del poder tardía de Foucault fue su giro biopolítico. Según Foucault, desde el siglo XVIII el poder adquirió una fisonomía y funcionalidad que privilegió el gobierno de las poblaciones y sus capacidades vitales. Con vistas a lograr un mejor funcionamiento social, el poder biopolítico promovió la producción y maximización de las capacidades de la vida humana tanto a nivel de los individuos como a nivel de los colectivos. Como lo demuestra el dispositivo educacional de gobierno de los sordos, las estrategias de maximización de las capacidades de los sordos se articularon complejamente con formas de control y autocontrol, clasificación, separación, encierro y administración normalizadora característicos del poder disciplinario.

En la sección 3 identifico algunos de los mecanismos de poder, lógicas de regulación y representaciones culturales que operan como microfundamentos de la educación oralista que promueve la constitución del sujeto sordo como un individuo adaptado y asimilado a la cultura oyente y facilita el gobierno de la población sorda. De este modo intento complementar el relato acerca del dispositivo educacional con una serie de otros conceptos críticos que a la vez suplementan y sirven de microfundamentos a la teoría sobre la gubernamentalidad en su descripción del gobierno de la población sorda. ${ }^{4}$

\section{EDUCACIÓN PARA SORDOS: MECANISMOS, LÓGICAS DE GOBIERNO Y REPRESENTACIONES CULTURALES}

En este apartado intentaré develar algunos mecanismos, lógicas de regulación y representaciones culturales que a la vez son efectos y participan del gobierno de los sordos

La combinación de conceptos analíticos y críticos de diferente procedencia teórica es legítima siempre y cuando dichos conceptos puedan ser acomodados bajo una misma ontología social y una epistemología común. Como podrá ver el lector atento a estas distinciones, la batería de conceptos analíticos y críticos que aquí utilizo comparten una ontología social antifundacionalista y antiesencialista y una epistemología constructivista, razón por la que me parece posible suplementar con ellos la perspectiva general de la gubernamentalidad. 
por medio de la educación. ${ }^{5}$ Me referiré a la diferenciación funcional de la educación especial, su medicalización, la intervención legitimatoria de los saberes expertos, al imperialismo cultural del discurso oyente que se expresa en el discurso liberal sobre la ciudadanía, el audismo y la estigmatización y estereotipación del sordo como formas de violencia simbólica. ${ }^{6}$

\section{1. Saberes Expertos, Práctica Clasificatoria y Pedagogía Especial de Sordos}

En la educación de sordos intervienen saberes expertos, como los discursos pedagógico, psicopedagógico y médico que legitiman e institucionalizan el conocimiento sobre la sordera y los sordos. Estos saberes intervienen en la práctica educativa cotidiana como formas de conocimiento científico-práctico que en su aplicación han contribuido a definir, separar (o integrar) y regular a la población de sordos. Dichas prácticas de clasificación no son inofensivas (Dolnick, 1993; Hacking, 1986; Pray y Jordan, 2010). Las categorías especiales de individuos -como la de sordos- son constructos sociales que se forman a partir del contraste con una categoría privilegiada -como la de individuos oyentes o simplemente "normales" (Arneil, 2009; Hacking, 1986)-. En la formación de las categorías sociales de oyentes, sordos, hipoacúsicos, etc., participan saberes como la medicina y las ciencias cognitivas, instituciones como las escuelas especiales y los hospitales, y expertos como los psicopedagogos y los médicos (Herrera, 2008; 2011; Lane, 1984; 1992; Ladd, 2003; Sacks, 2003). Esta operación de clasificación, conjuntamente ejecutada por saberes, instituciones y expertos, contribuye a generar inequidades y privilegios entre las categorías de individuos (Hewitt, 2001). Por su parte, las categorías sociales producen efectos distributivos de privilegios y desventajas que redundan en distinciones y tienen efectos positivos de reconocimiento y emancipación, o negativos de invisibilización, negación y opresión de grupos humanos. Estos efectos de distinción y jerarquía entre sordo y oyente son invisibilizados por los criterios de neutralidad y objetividad científica, eficacia, cuidado y benevolencia con que dicen conducirse las instituciones, los expertos y la producción de conocimiento en el campo de la sordera (Herrera, 2008; 2011; Lane, 1984; 1992; Ladd, 2003; Sacks, 2003; Sparrow, 2005). Además, la jerarquía entre oyente y sordo, aunque parezca natural, es en verdad contingente. Su estabilidad es el resultado de una larga historia de construcción social de las categorías con que pensamos la

5 No intento describir los supuestos de los principios pedagógicos enunciados por la educación especial de sordos, cuestión para la que la pedagogía crítica parece mejor armada que la teoría política.

6 La violencia simbólica se refiere a una forma de poder opresivo ejercido sobre personas o grupos subalternos con la aquiescencia de estos últimos. La violencia simbólica resulta de la ventaja con que cuentan en cada sociedad algunas personas y grupos a causa de su estatus privilegiado en la estructura de divisiones sociales. En otras palabras, el concepto de violencia simbólica es útil, pues enfatiza que la opresión que sufren algunos grupos desventajados es concomitante con los privilegios de otros grupos favorecidos. La violencia simbólica no requiere un ejercicio de la violencia física, en parte debido a que los subalternos la aceptan como si fuera natural (Bourdieu, 1996; 2000). De este modo, el concepto de violencia simbólica enfatiza los efectos conjuntos de división social, distinción y aceptación de la subordinación. Así, la opresión y desventaja relativa de los sordos es concomitante con la ventaja de las personas oyentes que ocupan posiciones privilegiadas en una sociedad dominada por oyentes en la que los sordos carecen de las mismas oportunidades y privilegios que los oyentes. 
experiencia del cuerpo en la modernidad, y no es el resultado de la pura biología. ${ }^{7}$ Este carácter contingente de la identidad ayuda a explicar las concepciones de la sordera como una discapacidad y como identidad étnico-lingüística.

Considérese el caso de la incuestionada neutralidad científica de la pedagogía. El conocimiento científico en este campo se presenta como "un saber que da cuenta del objeto" cuya verdad estaría libre de todo dogma, convirtiéndose así en "un problema técnico, políticamente neutral" del que pueden derivarse tranquilamente cursos de acción seguros y carentes de sesgos (Grinberg, 2008: 45). Coincidente con ese halo de cientificidad técnica, las propuestas y políticas públicas en el campo de la educación de los sordos aparecen como carentes de voluntad de poder y libres de toda perspectiva valórica específica. Ahora bien, esta premisa de neutralidad educativa justificada en el conocimiento médico, psicológico y pedagógico que engendra visiones y prácticas aparentemente universalistas e integradoras, también involucra una velada promesa progresista de realización total de la humanidad. En efecto, el que este conocimiento se presente como neutro, científico y no ideológico no quiere decir que en verdad pueda carecer de supuestos normativos. Estos existen siempre, pero muchas veces son implícitos. En efecto, la educación especial para sordos, pero también la educación de integración, sustentan una imagen del sujeto humano normal que funciona como ideal regulatorio y normalizador. No podemos olvidar que la acción educativa no solo distribuye saberes y confiere a las personas conocimientos tenidos por necesarios, sino que, en tal proceso, además produce "una determinada subjetividad" (Grinberg, 2008: 41; también Foucault, 1977).

\section{2. Diferenciación y Medicalización de la Educación de Sordos}

La educación especial de sordos es una respuesta de diferenciación funcional al requerimiento de otorgar educación e integrar a una minoría de sordos que coexisten con la mayoría de oyentes en sociedades complejas y heterogéneas. Más que contraria a la totalización y estandarización del poder disciplinario de las instituciones de encierro como son los internados para sordos, la educación de sordos se ha convertido en un dispositivo de control complementario y sofisticado, capaz de realizar una sintonización fina con las características de diferentes tipos de cuerpos e individuos y sus necesidades de adaptación al sistema (Deleuze, 1996; Foucault, 2001). Los conocimientos expertos -medicina, audiología y foniatría, pedagogía, educación especial, psicolingüística, ciencias cognitivas- contribuyen a este gobierno específico de la población sorda. Se distingue así entre individuos que son sordos profundos o sordos prelingüísticos, de los hipoacúsicos y sordos postlingüísticos. También se identifica a quienes pueden ser candidatos a recibir

Aunque la biología tiene mucho que decir en ello. Por razones de espacio no es posible abordar acá la relación entre materialidad y construcción social de la sordera. Para una perspectiva constructivista, ver Lane (1992) y Pray y Jordan (2010). Para una posición que otorga mayor peso a la materialidad de la biología del sordo, ver Dolnick (1993). 
un implante coclear ${ }^{8}$ con el entrenamiento necesario para su provecho de quienes no pueden. Se aplican tests audiométricos, psicológicos y de inteligencia para realizar un diagnóstico preciso que permita definir el tratamiento adecuado. A nivel macro, se realizan censos y aplican encuestas con recursos estatales con el propósito de saber quiénes son los sordos, su edad, género, nivel de ingreso, educación, si son urbanos o rurales, etc. Esta lógica de clasificación y tratamiento es una condición de posibilidad para que la educación para sordos funcione como un dispositivo diferenciado que se modula y adapta plásticamente con el objetivo de obtener un efecto general: el gobierno de toda la población (incluidos los sordos).

Pero, por otra parte, se observa que esta diferenciación de la educación oralista de sordos no ha consolidado criterios propios de funcionamiento, sino que ha sido objeto de colonización por parte del saber médico. La medicalización (Conrad, 2007) de la educación especial para sordos somete al saber pedagógico a los criterios a la vez patologizantes y terapéuticos de la medicina y la psicología (Dolnick, 1993), y con ello amenaza la autonomía de los criterios pedagógicos (Herrera, 2011). Estos saberes han contribuido hasta tiempos muy recientes a la cristalización de la imagen del sordo como persona deficitaria y discapacitada que, en lugar de ser segregada o encerrada debido a su anormalidad, debe ser integrada a la sociedad de manera lo más plena posible. El dispositivo educacional oralista promueve la integración de los sordos por medio de su normalización (Foucault, 1977). Esta orientación a la integración se manifiesta de manera más radical aun en el caso de aquellos que son normalizados por medio de dispositivos tecnológicos como el implante coclear.

Esta concepción de la sordera y la educación de personas sordas es consistente con la responsabilización del individuo típica de los regímenes biopolíticos neoliberales, para los que este debe hacerse cargo de su condición. En estos esquemas de seguridad social y sistema sanitario la mantención de la salud y la condición corporal de autonomía es una responsabilidad y un asunto crecientemente individual y de elección, especialmente si los dispositivos educativos y tecnológicos -como los audífonos e implantes coclearesestán disponibles. En esta perspectiva, gracias a los avances de la educación oralista y las nuevas tecnologías la condición de sordo podría dejar de ser un destino trágico. La condición de sordera sería más maleable y permitiría a los individuos, idealmente al menos, adecuarse e integrarse socialmente. Así, el buen ciudadano sordo sería aquel que se integra a la sociedad oyente. Este ideal motiva una imagen moralizante, culposa y potencialmente sancionadora que estigmatiza a aquellos sordos que se resisten a las prácticas promovidas por el régimen de subjetividad y de ciudadanía imperante que impone la adaptación a la oralidad.

8 El implante coclear es una tecnología que permite codificar los sonidos del exterior en señales eléctricas que llegan directamente al nervio auditivo. A diferencia de los audífonos que son útiles para los hipoacúsicos, el implante coclear se plantea como una solución para los sordos profundos. Su implantación requiere de una intervención quirúrgica que involucra algunos riesgos. La principal crítica de los Sordos contra el implante coclear es que conlleva el riesgo de la desaparición paulatina de su comunidad y cultura. 


\section{3. Universalización e Imperialismo Cultural Oyente: El Discurso Liberal y la Ciudadanía}

Recientemente la teoría política se ha preocupado de las minorías de discapacitados y ha criticado los supuestos racionalistas de la filosofía política liberal (pero también de la republicana y comunitaria) que modela el concepto dominante de ciudadanía democrática moderna. Este concepto de ciudadanía favorece la racionalidad y autonomía del sujeto como valores en detrimento de otros principios posibles como el cuidado (Kittay, 2009) o la apertura a la diferencia y la sorpresa (Bérubé, 2004). Las perspectivas críticas de Arneil (2009), Nussbaum (2007; 2009) y Kittay (2009) se han dirigido a repensar los fundamentos excesivamente racionalistas de la constitución del ciudadano o sujeto político a partir de los desafíos que plantean las discapacidades cognitivas. En todos estos casos, el blanco de la crítica ha sido el presupuesto a la vez kantiano y liberal de la racionalidad como característica constitutiva de lo humano. Sin embargo, no se ha explorado de manera suficiente la relación entre racionalidad y lenguaje oral. Esta relación, que define el núcleo de la representación cultural del ciudadano moderno y de la política democrática, se encuentra esencializada, sedimentada, naturalizada y su contingencia olvidada. Más aún, el discurso político liberal (pero también otras tradiciones como el republicanismo y el comunitarismo) anclan este ideal democrático y ciudadano en profundas creencias acerca de la esencia racional y oral de la vida humana. Esta lógica ha sido resumida por Bauman (2004) en el siguiente silogismo:

El lenguaje es humano/

el habla es el lenguaje/

quienes no hablan no son humanos.

El imperialismo cultural (Lugones y Spelman, 1983; Said, 1977; Young, 1990) es experimentado por los sordos como resultado de la universalización de la experiencia oyente. ${ }^{9}$ Así se asume como la norma la figura abstracta del ciudadano ideal con las competencias auditivas y orales requeridas para entender y expresarse de manera oral o escrita en la esfera pública. Este modelo es obviamente inadecuado para quienes tienen el lenguaje de señas como lengua natural. Esta imagen de sentido común del ciudadano oyente y del oralismo se impone como modelo ideal a la comunidad de personas sordas y es experimentado como una representación opresiva y a la vez invisiblizadora de la diferencia de los $\mathrm{S} /$ sordos.

El imperialismo cultural oyente puede también ser comprendido como el efecto de la naturalización de la experiencia cultural de la población oyente y su mundo simbólico. De este modo el mundo cultural oyente y las conductas de los oyentes son asumidos como "lo normal". Su imposición a los sordos se manifestó en la educación oralista que les prohibió o inhibió el desarrollo del lenguaje de señas y, en su lugar, fomentó el

Arneil (2009) desarrolla un argumento similar referido al ideal de ciudadano racional. Las conexiones entre racionalidad y oralidad/lectoescritura son relevantes para este caso, pero acá podemos por razones de espacio apenas afirmar su existencia tanto en el discurso de la teoría política como en el discurso de las ciencias cognitivas y la pscicopedagogía (sobre esto último, ver Herrrera, 2008 y 2011). 
aprendizaje de la lectura de labios, la lectoescritura, y el habla. De este modo, el dispositivo educativo ha promovido la universalización del modelo de individuo y ciudadano oyente entre los sordos, asimilándolos en el doble sentido: integrándolos a la sociedad oyente -sin demasiado éxito por cierto- y transformándolos para que los sordos se asemejen a los oyentes. Esta asimilación de los sordos por medio de la educación oralista ha sido justificada como un logro civilizatorio; y sin embargo, al negar las diferencias tanto culturales como de experiencia del cuerpo de los S/sordos, oprime su identidad.

Además, al ser asumida la experiencia oyente como lo normal, se facilita la representación de la sordera como deficitaria y, por lo tanto, como anormal y necesaria de ser corregida y regulada. El régimen de ciudadanía dominante, racionalista y oyente, tiene un efecto a la vez moralizante, estructurante y opresivo en la formación del sordo que es representado únicamente en los términos de la cultura oyente, negándose así otras imágenes alternativas de los sordos que los representan con sus propios medios, códigos y significados. Esta negación de otras representaciones alternativas de los sordos reproducen dos imágenes: una del ciudadano normal (ideal) y otra del sordo como un sujeto que para desarrollar su potencial debe asimilarse al ideal de ciudadano oyente, por lo que debe ser oralizado. Estas imágenes perpetúan una oposición binaria que es además una jerarquía entre el oyente y su cultura, y el S/sordo y la cultura Sorda. El sistema de creencias en que se sustenta esta jerarquía naturalizada es el audismo.

\section{4. El Audismo como Sentido Común}

Según Harlan Lane, "el audismo (audism) es el modo oyente de dominar, reestructurar y ejercer autoridad sobre la comunidad sorda" (1992: 43). Lane (1992) vincula el audismo con el colonialismo como forma de opresión cultural por su inhabilidad para reconocer como característica fundamental de su cultura distintiva el uso que hace la comunidad sorda del lenguaje de señas. Aún más, el audismo enmascara, oculta este rasgo cultural propio de la cultura Sorda. Funciona como una ideología en el sentido específico de naturalización de la cultura oyente y de invisibilización de la cultura Sorda, de su autenticidad y valía moral. ${ }^{10}$ Por ello, el audismo parece estar a la base del imperialismo cultural oyente. ${ }^{11}$

10 Acá uso el concepto de autenticidad en el sentido de Dahmoon (2007, 54-55), quien deconstruye su significado criticando la tendencia de autores como Taylor (1994) a enfatizar las nociones de origen y profundidad.

11 Foucault (2000b, 136-137) y Laclau (1996, 201-220) coinciden desde diferentes frentes antifundacionalistas en que la crítica de la ideología como falsa conciencia es problemática. Haciéndome eco de ello, el uso específico que doy al concepto de ideología en relación con el audismo se deriva de Laclau (1996). Laclau se pregunta si al rechazar la noción de falsa conciencia porque no es posible afirmar una verdad, estamos obligados también a rechazar toda noción de distorsión. Con Laclau, considero que existe una forma de distorsión que puede ser caracterizada de ideológica y que es propia de todo aquel discurso totalizante que ilusoriamente pretende clausurar la realidad social y naturalizar una "normalidad" o una "verdad", como sucede con el audismo. El audismo distorsiona en este sentido específico al invisibilizar la heterogeneidad social -negando así la especificidad de la cultura Sorda- y al ocultar la contingencia del orden social y simbólico dominante -fomentando así la ilusión de la naturalidad del orden oyente-. En este sentido específico, este concepto crítico de la ideología como discurso totalizante se distingue del de la crítica de la ideología como falsa conciencia. Sostengo que este uso específico que hago de la noción de ideología para referirme al audismo como sentido común de la cultura dominante es coherente con la noción de postcrítica y con los supuestos epistemológicos y ontológicos de los estudios de Foucault (ver también los argumentos de Hoy (2004) sobre postcrítica). 
Según Humphries, el audismo es el supuesto ideológico de la supremacía del oyente o de aquellos que actúan como los oyentes por sobre los sordos (1977:12, citado en Pray y Jordan, 2010). El audismo incluye una cierta actitud fundada en la medicalización patologizante que estigmatiza -en el sentido negativo de Goffman (2006)- a todo aquel que no escuche (Humphrey and Alcorn, 1995: 85). Incluso personas sordas pueden fomentar -muchas veces de modo inconsciente- el audismo, como ocurre con quienes han recibido un implante coclear (Sparrow, 2005).

El audismo actúa como la doxa (Bourdieu, 1977) o el sentido común (Gramsci, 1971), es decir, como un patrón de supuestos inconscientes que establece aquello que se da por sentado en una cultura. Por ello se encuentra muy difundido y afecta tanto a la conciencia práctica de las personas como a los conocimientos expertos de la medicina o la psicopedagogía. Aún más, el audismo se apoya en los roles, instituciones y conocimientos expertos de profesionales y administradores, educadores, médicos, psicoterapeutas y psicopedagogos, audiólogos y foniatras, trabajadores sociales y funcionarios públicos. El audismo se expresa en formas de tratar a los sordos, de referirse a ellos, de representarlos y autorizar imágenes que los describen, y en formas de gobernarlos. Su arista más perniciosa es que frecuentemente opera de manera inadvertida por vía de la benevolencia que, de modo inconsciente, despolitiza y "discapacita" a la comunidad de sordos (Lane, 1992). El audismo se ha expresado también en la política pública de educación especial para sordos que ha promovido la oralización, normalización e inserción de los sordos al mundo "civilizado" de los ciudadanos oyentes (Pray y Jordan, 2010).

\section{5. La Estigmatización y Estereotipación de los S/sordos}

Las personas sordas, como otras personas con capacidades especiales y condiciones crónicas, suelen ser percibidas no solo como diferentes sino como anormales. Esta percepción puede ser comprendida como un estigma social (Goffman, 2006), es decir, como fruto de un juicio social negativo o rechazo severo dirigido hacia una persona o grupo. El estigma se construye sobre la base de la percepción por parte de los normales de las características distintivas del o de los individuos estigmatizados; es decir, de aquellos que se desvían de la norma social o cultural. La formación del estigma se realiza sobre la base de las expectativas y percepciones de los normales que, según Goffman, son simplemente aquellos que no se distancian de las expectativas sociales vigentes. El estigma produce una representación del otro como manchado, incompleto, imperfecto o desviado. Goffman pone especial énfasis en las metáforas e imágenes que suelen condensar la representación social de los estigmatizados. En el caso de las personas sordas, algunas de estas figuras de estigma más frecuentes son "sordomudo", "enfermo" y "discapacitado".

La lógica que subyace a la estigmatización de los sordos es el audismo. A su vez, el supuesto lógico del audismo es que el lenguaje oral es constitutivo de la identidad humana. Una consecuencia práctica del audismo es que tenemos un lenguaje negativo para referirnos a la sordera, por lo que la concebimos como un problema. Se da pie así a la formación de una oposición binaria entre oyente y sordo que está a la base de nuestra cultura y que construye una serie de polaridades opresivas. 
La afirmación de la superioridad del individuo oyente como sujeto completo sobre el sordo como deficitario, confluye con aquella sobre el carácter superior del lenguaje oral respecto de la lengua de señas. Estas distinciones fundamentales dan origen a una serie de oposiciones binarias que son mutuamente confirmatorias y de carácter ideológico. Estas oposiciones binarias son constitutivas de jerarquía e inequidades: si es sordo, es anormal, tiene un déficit, no habla adecuadamente y es incapaz de comunicarse, trabajar, educarse, carece de cultura, es salvaje, tiene un intelecto limitado, etcétera.

En conjunto, estas nociones son constitutivas de las representaciones altamente simplificadoras de la identidad oyente y sorda. Este efecto de simplificación, que niega la heterogeneidad de la realidad, es característico del proceso de estereotipación (Hall, 1997). Así, por ejemplo, se sigue reproduciendo la imagen del sordomudo, aun cuando la sordera solo se refiera a la incapacidad para oír, o la idea ciertamente algo más positiva pero igualmente simplificadora de que los sordos son buenos con las manualidades o el diseño visual. Decimos "algo más positiva", pues es característico de la estereotipación que estas atribuciones positivas explícitas tengan implícitamente connotaciones negativas. Así, la afirmación de que los sordos son buenos con las manualidades tiene implícitamente la connotación de que no son buenos en el trabajo intelectual y que su cognición concreta solo los habilita para el trabajo con las manos.

Estas representaciones tienen un efecto estructurante del sentido común y apoyan la naturalización del audismo que oprime a la población sorda y privilegia a la población oyente. Y aunque esta supremacía se encuentra cuestionada en nuestros días por el trabajo conjunto de movimientos radicales de Sordos, las ciencias de la educación y las ciencias sociales críticas, la concepción dominante en la conciencia práctica y los hábitos en nuestras sociedades y en muchas instituciones educacionales sigue siendo la de la superioridad de la oralidad. Desde la perspectiva oralista, que aún domina la formación de los sordos, se concibe a

... los estudiantes sordos como personas desviadas de la norma, carentes de lenguaje y de inteligencia e igualmente sostiene la dependencia unívoca entre el lenguaje oral y el desarrollo cognitivo y asume que las lenguas de signos son sistemas lingüísticos incompletos cuyo uso impide el aprendizaje de la lengua oral (Herrera, 2008: 215).

Si la oralidad es representada como el único medio para el conocimiento y adquisición cultural, casi necesariamente se considera al sordo y su lenguaje como ineficaz para poder conocer el mundo. Más aún, la preponderancia de la oralidad nos ha llevado a considerar -ya sea explícita o implícitamente- que el lenguaje de señas no puede representar el mundo sino de modo erróneo. Así, el lenguaje de señas se erigiría como un verdadero obstáculo para el conocimiento y, consecuentemente, el sujeto sordo sería un anormal cuya aparición interrumpiría el transcurrir normal del tiempo educativo necesario para el cultivo del individuo.

Este menosprecio por el lenguaje de señas como medio legítimo de aprendizaje y vehiculización de conocimientos y tradiciones ha facilitado la estigmatización y estereotipación de los sordos, quienes han llegado a ser incluso animalizados por 
sus educadores. En efecto, no son pocas las experiencias relatadas por exalumnos de escuelas para sordos que señalan que sus educadores/as les golpeaban sus manos cada vez que intentaban comunicarse en lengua de señas, argumentando que esta forma de comunicación pertenecería a monos (Herrera, 2012; Herrera, 2010:213; ver también Dolnick, 1993; Humphries y Padden, 2005; Restuccia, 2011). Esta figura connota la identidad del sordo como deficitaria, incompleta, salvaje o incivilizada e incluso como no humana y animal. Así, el sordo es representado como un individuo desviado de la norma de conducta humana y, por lo tanto, como alguien que debe ser corregido y civilizado. La lengua de señas, por su parte, ha sido pensada como una mímica, y sus capacidades cognitivas menospreciadas. Y aun cuando sus cuerpos sean humanos, los sordos no serían del todo humanos, pues al no poseer oralidad carecerían de un rasgo definitorio de la humanidad.

\section{6. Civilización, Ciudadanía y Oralidad}

En la sección "Universalización e Imperialismo Cultural Oyente: El Discurso Liberal y la Ciudadanía", ya he sugerido que la estrecha relación entre ciudadanía, oralidad y civilización, que ha sido naturalizada por la cultura política moderna, favorece la invisibilización y negación de la cultura Sorda. Tanto esta relación naturalizada como la negación de la cultura Sorda y los S/sordos son reconocibles en las instituciones y prácticas de la democracia representativa moderna. La democracia moderna se construye sobre la práctica deliberativa y un ideal de ciudadano racional, autónomo, oyente, con capacidad de leer y escribir, y de deliberar oralmente. Más aún, en no pocas ocasiones la práctica política en la democracia moderna ha sido concebida fundamentalmente como una forma de acción comunicativa oral. ${ }^{12}$ Más aún, la oralidad es a la vez una competencia, una expectativa y un supuesto de la ciudadanía democrática contemporánea. En efecto, las capacidades de los ciudadanos de criticar, protestar, reclamar, solicitar, defender y mantener posiciones, ofrecer, negociar, prometer, etc., están profundamente vinculadas a habilidades comunicativas orales. Pero no son solo estas actividades comunicativas políticas las que han sido diseñadas desde y para el lenguaje oral. También lo han sido las instituciones democráticas, el aparato burocrático estatal y la mayor parte de las organizaciones de la sociedad civil. Por lo tanto, aunque los sordos no tengan prohibición de, por ejemplo, votar, trabajar, educarse, y aunque sean ciudadanos de pleno derecho, debido a que su lenguaje natural es el lenguaje de señas y no el lenguaje oral, se encuentran en condiciones desventajadas e injustas. ${ }^{13}$

La relación entre ciudadanía, oralidad, civilización y modernidad también es identificable en la teoría de la ciudadanía. Considérese, por ejemplo, el clásico ensayo Ciudadanía y Clase Social (1997[1950]) de Thomas H. Marshall. En él, Marshall se refiere en repetidas

12 Enfoques muy distintos sobre la política democrática, como son los de Habermas (1994), Laclau y Mouffe (1985) y Young (1997) comparten este interés por la política en tanto acción comunicativa argumentativa.

13 Los sordos se enfrentan con innumerables dificultades para informarse y comprender los más fundamentales debates políticos que circulan casi exclusivamente por medios oral y escrito. También se los margina del mercado del trabajo y tienen dificultades para acceder a más altos niveles de educación formal. 
ocasiones a la extensión de la ciudadanía como la incorporación de nuevos individuos a un modo de vida civilizado por medio de la educación y la adquisición de hábitos correctos y el diálogo en lugar del conflicto frontal (pp. 301, 303, 311). Marshall también describe la función evaluativa que cumple en las sociedades la imagen ideal de ciudadanía (p. 312-313). Este ideal de ciudadanía ha tenido un impacto en la educación de los sordos. En palabras de Louis di Carlo, uno de los autores clásicos sobre la sordera, la estrategia educativa oralista tuvo por objetivo proveer al niño de herramientas comunicativas que le permitirían

convertirse en un ciudadano de primera clase: adaptado, con pensamiento crítico y económicamente productivo en una sociedad mayoritaria fuera del contexto único de los sordos (1964: 85).

Como vemos, el modelo educativo oralista supone una visión de ciudadano ideal parlante, racional, productivo y autónomo. En consecuencia, la constelación de ciudadanía, oralidad y civilización en la modernidad ha influido los planes educativos oralistas de integración de los sordos, los que han tenido un efecto a la vez moralizante y de regulación.

Otro aspecto de este régimen de ciudadanía liberal es que los sordos experimentan varios de sus derechos y garantías como meras formas legales y jurídicas referidas a una figura puramente abstracta de ciudadanía, que en la práctica no los habilita para informarse adecuadamente y acceder a sus derechos debido a que solo una minoría de ellos puede entender el habla y expresarse oralmente. La mayoría de los sordos no son bilingües, no tienen altos niveles de lectoescritura, pueden expresarse oralmente y comprender el habla solo con gran dificultad, y un número no despreciable usa el lenguaje de señas -su lengua natural-o alguna técnica que combina lenguaje de señas y deletreo digital en lugar de la expresión oral.

El ideal de integración de los sordos en el mundo oyente signado por el oralismo y el audismo, ha sometido a generaciones de sordos a un proceso largo y en ocasiones doloroso de cultivo correctivo, que involucra el aprendizaje de la lectura de labios, la lectoescritura, del habla y el vocabulario de la lengua de los oyentes, la correcta modulación de las palabras, para nombrar solo algunas de las competencias que les son inculcadas a los sordos de manera opresiva. ${ }^{14}$ La educación oralista funciona como un dispositivo opresivo que produce y reproduce el imperialismo cultural oyente. Cabe entonces preguntarnos, ¿cuál es el nivel de éxito de esta tarea supuestamente civilizatoria del sordo? ¿Puede el dispositivo educacional oralista cumplir su promesa, que es borrar las diferencias entre los oyentes y los sordos? ¿Logra el sordo "civilizado" convertirse en un sujeto completamente funcional? oyente que sin entrenamiento intenta leer los labios. Pray y Jordan (2010) reportan que solo entre $25 \%$ y $35 \%$ de las palabras en inglés son identificables en el movimiento de los labios. De manera similar, en castellano palabras como mamá y papá son prácticamente indistinguibles a la vista. Un entrevistado señaló que la lectura de labios es una tarea agotadora, pues parte importante del éxito parece depender de la anticipación y contextualización de significados, con los que la tarea se parece a una permanente interpretación, adivinación del contenido, y su corrección posterior. Aprender a hablar para un sordo prelingüístico equivale a intentar imitar los sonidos del habla sin un feedback directo y sin memoria alguna acerca de cómo suena su pronunciación. 
¿O solo logra "disimular" su diferente condición lo suficiente como para volverse alguien aceptable? ¿Desaparece con su cultivo, su integración y asimilación la mácula de su "déficit" (que es déficit solo a los ojos de los oyentes y de los sordos "asimilados")? Estas preguntas han sido respondidas por varios especialistas indicando el fracaso del oralismo, que no logró cumplir la promesa de integración (Ladd, 2003; Lane, 1993; Pray y Jordan, 2010) y que en la actualidad amenaza a la cultura Sorda por medio de intervenciones tecnológicas y médicas como el implante coclear (Sparrow, 2005).

Tal vez más importante que las preguntas antes enunciadas está el cómo una cultura construye el significado de la sordera. En efecto, tal construcción afecta no solo cómo los sordos son tratados, sino también tiene un poderoso efecto en cómo los propios sordos se ven a sí mismos y a otros sordos..$^{15}$ Desde temprana edad, los niños sordos internalizan las representaciones que otros -padres, educadores, otros sordos, familiarestienen acerca de la sordera. Esto explica también la discriminación que los propios sordos hacen respecto de particulares categorías de personas sordas (Pray y Jordan, 2010). Por ello, tal vez lo más grave de las representaciones negativas de la sordera es que pueden convertirse en autoimágenes, afectando la autocomprensión y estima de los sordos y contribuyendo a la reproducción de las condiciones que hacen posible su opresión, invisibilización, estigmatización y exclusión. El dispositivo educacional oralista tiene una especial función de interpelación del sordo que facilita la identificación con la introyección de estas autoimágenes negativas que niegan la cultura Sorda. Así, la violencia simbólica de la cultura oyente contra la cultura Sorda se ejerce en ocasiones con la aquiescencia de no pocos sordos.

Tabla 1: Audismo y Oposiciones Binarias Constitutivas de la Identidad Sorda

\begin{tabular}{ll}
\hline Oyente & Sordo \\
Normal & Anormal \\
Completo & Deficitario \\
Lenguaje oral & Mímica comunicativa \\
Humano & No humano \\
Civilizado & Salvaje \\
Capaz & Discapacitado/ incapaz \\
Intelecto & Manualidad \\
\hline
\end{tabular}

\section{LA RESISTENCIA DE LOS SORDOS}

Este artículo ha afirmado que la educación oralista funcionó como un dispositivo de gobierno de los sordos y promovió por más de un siglo su asimilación sobre la base de un modelo oralista y biomédico, y su integración social apoyada en un patrón cultural oyente. El dispositivo educacional oralista es una encarnación muy concreta de la 
gubernamentalidad biopolítica. Pero, por otra parte, como Foucault frecuentemente afirmó, allí donde hay poder también hay resistencia (2000a). Más aún, desde un punto de vista analítico el poder como concepto tiene sentido solo en tanto sabemos que se ejerce sobre individuos libres con capacidades (Foucault, 2000a; 2001). ${ }^{16}$

Las estrategias de resistencia y las prácticas de libertad de los Sordos y sus organizaciones han sido promovidas por activistas y académicos críticos como Paddy Ladd y Harlan Lane, y apoyadas por instituciones como la Universidad Gallaudet. El desarrollo más interesante de las prácticas críticas y asociativas de los Sordos se basa en formas de autocomprensión gestadas en su propia cultura. Estas prácticas se han generado como una respuesta a la historia de opresiones de que han sido víctimas los sordos. En oposición a la educación oralista que es una manifestación del control biopolítico de la población sorda, la autocomprensión de las organizaciones de Sordos se basa en procesos naturales de socialización entre pares, en la gestación de una memoria colectiva de los Sordos y procesos de formación de una conciencia Sorda (consciousness raising). Sobre esta base, las organizaciones de Sordos promueven una forma distinta de ser persona que se construye a partir de la consideración del Sordo como un sujeto con un sentido de autovalía y como miembro de una comunidad con una identidad asentada en la Cultura Sorda. De este modo, encontramos a Sordos que no están dispuestos a ser formados en sistemas educacionales para oyentes que no respeten su forma natural de comunicación basada en el lenguaje de señas. De modo similar, se trata de sujetos que no aceptan asumir el rol de pacientes para "mejorar" o "curar" su condición de sordera. La formación de esta conciencia Sorda y el empoderamiento de las organizaciones de Sordos se ha visto además facilitada por el creciente cuestionamiento de la medicalización de la sociedad y del conocimiento médico y las disciplinas "psi". A ello se ha sumado la mayor legitimidad de formas de conocimiento basadas en la experiencia directa de las personas comunes.

Lo que distingue a estas organizaciones de Sordos es la presencia de una identidad cultural basada en la lengua de señas. Desde este punto de vista, el discurso de los Sordos pone en un segundo plano a la sordera como marca biológica. Sin embargo, a partir de mi porpia observación y estudio de organizaciones de Sordos en Chile, como son Mis Manos y CRESOR, he llegado a concluir que esta dimensión material y corpórea de la experiencia humana que llamamos "sordera" no deja de ser importante, y debe jugar un rol suplementario de la identificación principal con el lenguaje de señas y la cultura Sorda. Varias razones hay para ello, pero aquí solo aludiré brevemente a dos. En primer lugar, al destacar esta dimensión material y corpórea de la experiencia de los $\mathrm{S} /$ sordos evitamos el excesivo voluntarismo a que pueden llevar las visiones radicales de constructivismo social, que corren el riesgo de relativizar las muy concretas dificultades que enfrentan individualmente las personas sordas. En segundo lugar, el modelo lingüístico-cultural de la cultura Sorda, que ha sido modelado según el ejemplo de las minorías étnico-lingüísticas, no ha abordado suficientemente las diferencias que hay

16 Aquí apenas delinearé este tema por limitaciones de espacio. Este ha sido más desarrollado en la presentación no publicada. 
entre un grupo de sordos y un grupo étnico-lingüístico. Mientras en el caso de los últimos la cultura y la lengua se transmite en y entre las familias de manera intergeneracional, entre los sordos la transmisión no tiene que ver con el linaje. En un sentido que debe aún ser explorado más acuciosamente, estimo tentativamente que las adscripciones de los sordos a sus grupos de referencia se parecen algo más a la situación de socialización de las minorías sexuales que a la de las minorías étnico-lingüísticas. Lo que sí es claro, es que las luchas y demandas sociales que articulan la identidad de las organizaciones de Sordos no se dirigen a superar su "discapacidad", sino a afirmar su reconocimiento público y a destruir las fuentes de opresión, exclusión, estigma, y discriminación.

El activismo sociopolítico de los Sordos representado por organizaciones como Mis Manos y CRESOR articula una biopolítica afirmativa (que se opone a la gubernamentalidad biopolítica) y una política de la identidad y el reconocimiento cultural (que se opone a la invisibilización y negación de la diferencia de los Sordos y su cultura). Este activismo se expresa en la difusión y defensa de la memoria colectiva de los Sordos, la lucha por el reconocimiento de la lengua de señas y la cultura Sorda, y en el reclamo de algunos derechos ciudadanos fundamentales, como es el derecho a la información, a la educación y al trato igualitario. Esta política de identidad de los Sordos, más que politizar el cuerpo y la vida misma, repolitiza y "capacita" a los sordos como Sordos que afirman su singularidad e identidad, a la vez resistiendo a la gubernamentalidad biopolítica que, como hemos visto, genera discursos, estrategias, tácticas e instituciones específicas cuando se trata de personas sordas. Entre ellas, el dispositivo educacional oralista jugó un rol preponderante en los últimos 130 años, y solo empezó ya a ser cuestionado más seriamente desde la década de $1960 .{ }^{17}$

\section{CONCLUSIÓN}

Desde fines del siglo XIX, el gobierno de la población sorda ha incluido un amplio y heterogéneo rango de políticas públicas de educación que por lo general han favorecido la oralización y normalización de los sordos (Dolnick, 1993; Herrera, 2011; Humphreis y Padden, 2005; Lane, 1992; Pray y Jordan, 2010).${ }^{18}$ Esta orientación favoreció la formación del sujeto sordo según el modelo del ciudadano moderno ideal, autónomo, capaz de hablar de manera clara y deliberar racionalmente. ¿Qué implicancias ha tenido para el gobierno de las personas sordas el predominio de este imaginario de la ciudadanía? Entre sus múltiples efectos, nos concentramos en las consecuencias opresivas de los mecanismos de poder, las lógicas e regulación y las representaciones culturales que actúan en el gobierno de los sordos por medio del dispositivo educacional oralista. Vimos con algún detalle cómo la formación de saberes especializados, instituciones y expertos favorecen la clasificación

17 El rol crítico que han jugado instituciones como la Universidad Gallaudet e intelectuales sordos y oyentes como Stokoe, Lane, Ladd, Humphries y Padden ha sido fundamental. El artículo seminal de Stokoe (2005 [1960]) marca un punto de inflexión en la valoración del lenguaje de señas y la cultura de los Sordos.

18 Una excepción es la experiencia de la universidad para Sordos Gallaudet en USA (Dolnick, 1993; Humphries y Padden, 2005; Pray y Jordan, 2010). 
de poblaciones -oyentes, hipoacúsicos, sordos- y cómo se desarrolló, coherente con esas categorías, la educación especial para sordos. También vimos cómo la universalización del ideal oyente de ciudadano, sumados al audismo y la estereotipación de los sordos, ha producido efectos de imperialismo cultural que niegan la cultura Sorda.

Estos mecanismos de poder, lógicas de regulación y representaciones culturales se refuerzan mutuamente y apoyan el objetivo principal de la práctica educativa oralista, que es determinar el campo de acción de los sujetos y la producción de un modo de ser sordo adecuado para la sociedad oyente. He destacado que esta relación educativa supone la existencia de relaciones de poder, aun cuando sus discursos, prácticas, estrategias y tecnologías se articulen en el lenguaje de la benevolencia, la inclusión social y la formación de sujetos libres. Por ello se vuelve necesario "estudiar los procesos y prácticas de escolarización" y "de gobierno de producción y dirección de la conducta entendiendo que en ellas no hay nada aséptico" (Grinberg, 2008: 55). En esta perspectiva los sujetos no son entes ya constituidos sobre los que se impondrían unas prácticas educacionales en un segundo momento. En efecto, las identidades de los S/sordos no preceden a las prácticas sociales y discursos que los forman, y el dispositivo educacional y las políticas públicas de educación son fundamentales en este proceso de constitución del sujeto sordo y, desde la resistencia a estas últimas, también son fundamentales en la formación del sujeto Sordo.

Mientras la oralidad siga siendo representada en los imaginarios sociales educativo y médico como el único medio para el conocimiento y adquisición de la cultura y, por contrapartida, el lenguaje de señas lo sea como ineficaz para poder conocer el mundo, la asimetría entre ambas comunidades se reproducirá y el imperialismo cultural oyente impedirá el reconocimiento de la cultura Sorda. Por ello es que parecen relevantes los nuevos avances que se están realizando en el campo de la educación crítica desde las perspectivas de la educación bi-bi (bilingüe-bicultural), en tanto educa aceptando y respetando la propia visión que tienen los Sordos respecto de su cultura y proceso formativo (Herrera 2008; 2011; Ladd, 2003).

\section{REFERENCIAS}

Albrecht, Gary L. et al. (eds.). 2001. The Sage Handbook of Disability Studies. London: Sage.

Altman, Barbara M. 2001. “Disability Definitions, Models, Classification Schemes and Applications". En Sage Handbook of Disability Studies, Gary L. Albrecht et al. (eds.), 97-122. London: Sage.

Arneil, Barbara. 2009. "Disability, Self-Image and Political Theory". Political Theory 37 (2): 218-242.

Ball, Stephen J. (ed.). 1993. Foucault y la educación. Disciplinas y saber. Madrid: Morata.

Bauman, H-Dirksen. 2004. "Audism: Exploring the Metaphysics of Oppression". Journal of Deaf Studies and Deaf Education 9 (2): 239-246.

Berger, Ronald. 2013. Introducing Disability Studies. Boulder, CO: Lynne Rienner Publishers.

Bérubé, Michael. 2004. Citizenship and Disability. Dissent, Spring: 52-57.

Bourdieu, Pierre. 1977. Outline of a Theory of Practice. Cambridge: Cambridge University Press.

Bourdieu, Pierre. 1996. Distinction. A Social Critique of the Judgment of Taste. Cambridge, MA: Harvard University Press.

Bourdieu, Pierre. 2000. “Sobre el poder simbólico". En Intelectuales, Política y Poder, Pierre Bourdieu, 65-73. Buenos Aires, UBA/Eudeba. 
Conrad, Peter. 2007. The Medicalization of Society: On the Transformation of Human Conditions into Treatable Disorder. Baltimore: The Johns Hopkins University Press.

Dhamoon, Rita. 2009. Identity/Difference Politics. How Difference is Produced, and Why It Matters. Vancouver, Toronto: University Of British Columbia Press.

Deleuze, Gilles. 1996. "Post-scriptum sobre las sociedades de control". En Conversaciones, Gilles Deleuze, 277-292. Valencia: Pre-Textos.

Di Carlo, Louis M. 1964. The Deaf. New Jersey: Prentice-Hall.

Dolnick, Edward. 1993. "Deafness as Culture". The Atlantic Monthly, September: 37-53.

Foucault, Michel. 1977. Discipline and Punish: The Birth of Prison. London: Allen Lane.

Foucault, Michel. 2000a. Power. Edited by James D. Faubion. NY: The New Press.

Foucault, Michel. 2000b. "Verdad y Poder. Diálogo con M. Fontana". En Un diálogo sobre el poder y otras conversaciones, Michel Foucault, 128-145. Madrid: Alianza.

Foucault, Michel. 2001. "El Sujeto y el Poder". En Michel Foucault: Más allá del Estructuralismo y la Hermenéutica, Hubert Dreyfus y Paul Rabinow, 241-259. Buenos Aires: Ediciones Nueva Visión.

Garland-Thomson, Rosemarie. 1997. Extraordinary Bodies: Figuring Physical Disability in American Culture and Literature. New York: Columbia University Press.

Goffman, Erwin. 2006. Estigma. Buenos Aires: Amorrortu Ediciones.

Gordon, Colin. 1991. "Governmental Rationality: An Introduction". En The Foucault Effect: Studies in Governmentality, Graham Burchell et al. (eds.), 1-52. USA: University of Chicago Press.

Gramsci, Antonio. 1971. Selections From The Prison Notebooks. London: Lawrence \& Wishart.

Grinberg, Susana. 2008. Educación y poder. Buenos Aires: Miño y Dávila.

Habermas, Jürgen. 1994. "Three Normative Models of Democracy". Constellations 1 (1): 1-10.

Hacking, Ian. 1986. "Making Up People". En Reconstructing Individualism: Autonomy, Individuality and the Self in Western Thought, Thomas C. Heller et al. (eds.), 222-236. Stanford CA: Stanford University Press.

Hall, Stuart. 1997. "The Spectacle Of The Other". En Representation: Cultural Representations and Signifying Practices, Stuart Hall (ed.), 223-279. London: Sage.

Herrera, Valeria. 2011, Octubre. Entrevista a Valeria Herrera (Hernán Cuevas, entrevistador).

Herrera, Valeria. 2008. "Estudio de la población sorda en Chile: Evolución histórica y perspectivas lingüísticas, educativas y sociales". Revista Latinoamericana de Educación Inclusiva 4 (1): 211-226.

Hewitt, 2001. "Bio-politics and Social Policy: Foucault's Account of Welfare". En The Body: Social Process and Cultural Theory, Mike Featherstone, Mike Hepworth, Bryan S. Turne (eds.), 225-255. London: Sage.

Hoy, David Couzens. 2004. Critical Resistance. From Poststructuralism to Post-Critique. Cambridge, MA: MIT Press.

Humphrey, Jan y Alcorn, Bob. 1995. So you want to be an Interpreter: An Introduction to Sign Language Interpreting, 2nd edition. Amarillo, TX: H\&H Publishers.

Humphries, Tom. 1977. "Communicating Across Cultures (deaf=hearing) and Language Learning". Unpublished doctoral dissertation, Union Institute and University, Cincinnati, OH.

Huphries, Tom y Padden, Carol. 2005. Inside Deaf Culture. Cambridge, MA: Harvard University Press.

Kittay, Eva F. 2009. "The Personal is Philosophical is Political: A Philosopher and Mother of a Cognitively Disabled Person Sends Notes from the Battlefield". Metaphilosophy 40 (3-4): 606-627.

Laclau, Ernesto. 1996. "The Death and Resurrection of the Theory of Ideology". Journal of Political Ideologies 1 (3): 201-220.

Laclau, Ernesto y Mouffe, Chantal. 1985. Hegemony and Socialist Strategy. London: Verso.

Lane, Harlan. 1984. When the Mind Hears. A History of the Deaf. Nueva York: Penguin Books.

Lane, Harlan. 1992. The Mask of Benevolence: Disabling the Deaf Community. New York: Alfred A. Knopf.

Ladd, Paddy. 2003. Understanding Deaf Culture: In Search of Deafhood. Clevedon: The Cromwell Press.

Lugones, María y Spelman, Elizabeth. 1983. "Have we got a Theory for you! Feminist Theory, Cultural Imperialism and the Demand for 'the Woman's. Voice'". Women's Studies International Forum 6 (6): 573-581.

Marshall, Thomas H. 1997. “Ciudadanía y Clase Social”. REIS 79: 297-344.

Nussbaum, Martha. 2007. Frontiers of Justice: Disability, Nationality, Species of Membership. Cambridge, MA: Harvard University Press.

Nussbaum, Martha. 2009. "The Capabilities of People with Cognitive Disabilities". Metaphilosophy 40 (3/4): 331-351. 
Peters, Michael A. et al. (eds.). 2009. Governmentality Studies in Education. Boston: Sense Publishers.

Pray, Janet L. y Jordan, I. King. 2010. "The Deaf Community and Culture at a Crossroads: Issues and Challenges". Journal of Social Work in Disability \& Rehabilitation 9: 168-193.

Restuccia, Daniella. 2011. "La ciudadanía desde el silencio. Representaciones sociales y ciudadanía en personas con discapacidad auditiva". Tesis de Grado de Licenciatura en Ciencia Política. Escuela de Ciencia Política, Universidad Diego Portales.

Rose, Nikolas y Miller, Peter. 1992. "Political Power Beyond the State: Problematics of Government". The British Journal of Sociology 43 (2): 173-205.

Sacks, Oliver. 2003. Veo una voz. Viaje al mundo de los sordos. Anagrama: Barcelona.

Said, Edward. 1977. Orientalism. London: Pinguin.

Shakespeare, Tom. 2006. "The Social Model Of Disability". En The Disability Studies Reader, 2 a edición, Lennard Davis (ed.), 197-204. London: Routledge.

Stokoe, William. 2005 [1960]. "Sign Language Structure: an Outline of the Visual Communication System of the American Deaf". Journal of Deaf Studies and Deaf Education 10 (1): 3-37.

Sparrow, Robert. 2005. "Defending Deaf Culture: The Case of Cochlear Implants". The Journal of Political Philosophy 13 (2): 135-152.

Sparrow, Robert. 2010. "Implants and Ethnocide: Learning from the Cochlear Implant Controversy". Disability and Society 25 (4): 455-466.

Taylor, Charles. 1994. "The Politics of Recognition". En Multiculturalism. Examining the Politics of Recognition, Amy Gutmann (ed.), 25-73. Princeton University Press: Princeton, NJ.

Tremain, Shelley. 2001. "On the Government of Disability". Social Theory and Practice 27 (4): 617-636.

Weir, Allison. 2009. “Who are we?: Modern Identities between Taylor and Foucault". Philosophy and Social Criticism 35 (5): 533-553.

Williams, Gareth. 2001. "Theorizing Disability". En Sage Handbook of Disability Studies, Gary L. Albrecht et al. (eds.), 123-144. London: Sage.

Young, Iris. 1990. Justice and the Politics of Difference. New Jersey: Princeton University Press.

Young, Iris. 1997. "Asymmetrical Reciprocity: On Moral Respect, Wonder and Enlarged Thought". Constellations 3 (3): 340-363.

Hernán Cuevas es profesor de la Escuela de Ciencia Política de la Universidad Diego Portales, Santiago de Chile. PhD Universidad de Essex (Reino Unido). E-mail: hcuevasster@gmail.com 
